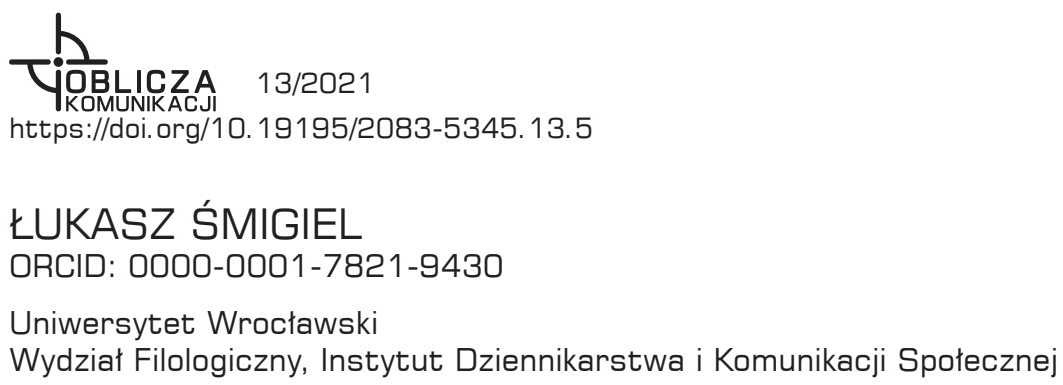

\title{
Filmowe cechy zwiastuna do książki
}

\begin{abstract}
Abstrakt
W szerszym ujęciu tekst dotyczy rosnącej popularności zwiastunów wideo do książek. Jego autor tłumaczy ich funkcje i określa miejsce w sferze kultury czytania. W ujęciu węższym - analizie poddano filmowe cechy trailerów literackich, które zostają zestawione z tradycyjnymi zwiastunami kinowymi. Artykuł poddaje wstępnej analizie różne aspekty techniczne produkcji tego rodzaju, ze szczególnym uwzględnieniem narzędzi typu cinematic book trailer. Omawiane zagadnienia wiążą się z kwestiami fundamentalnymi dla tworzenia skutecznej komunikacji w dynamicznie rozwijającej się przestrzeni online: komunikacji pomiędzy czytelnikami, autorami a producentami książkowych zwiastunów, które w najbliższym czasie mogą stać się jedną z bardziej popularnych i dopracowanych form promocji literatury $\mathrm{w}$ internecie.
\end{abstract}

Słowa kluczowe: książka, teaser, paratekst, komunikacja, trailer, kultura czytelnicza, reklama, promocja, czytelnictwo, książka w internecie, zwiastun filmowy.

\section{Wprowadzenie. Nowe technologie w czasach pandemii}

Pandemia zmieniła świat na wielu poziomach. Mocno wpłynęła także na rozwój technologiczny, a w szczególności na sposoby komunikowania się i przekazywania sobie informacji online. Wraz z nową technosferą zaczyna się rozwijać nowa infosfera. Musi to wywierać ogromny wpływ na sferę ważniejszą od wszystkich innych; tę, która mieści się w ludzkich głowach (Toffler 1986: 161) — jak pisał już w 1980 roku Alvin Toffler w słynnej Trzeciej fali. Jest to hipertekstowa przestrzeń trudna do opisania, bo nieustannie pojawia się w niej coś nowego, na przykład nowe parateksty, jak wideo podcasty czy seriale audio. Internet - z medium, które w pewnym sensie próbowało zastąpić książki, kino czy koncerty — stał się nagle podstawową platformą w ogóle umożliwiającą jakikolwiek dostęp do dóbr przemysłu kulturalnego, opisywanego w Dialektyce oświecenia przez Maxa Horkheimera i Theodora Adorna. 
Do powszechnego użytku trafiły platformy edukacyjne i szkoleniowe służące między innymi do zdalnego nauczania, należące do wielkich koncernów, jak Google czy Microsoft, oraz do mniejszych firm, jak Zoom. Pojawiły się niezwykle rozbudowane aplikacje do tworzenia prezentacji, platformy do słuchania podcastów audio i wideo, wirtualne koncerty, targi i konferencje. Wydaje się niemożliwe, aby tak globalne zmiany w zakresie technologii nie wpłynęły również na rynek książki i kulturę czytania. I rzeczywiście - także i na tej płaszczyźnie ostatnie miesiące pozwalają nam zaobserwować wręcz rewolucyjne zmiany w podejściu do książki i czytelnictwa.

Wydawcy i księgarnie, znalazłszy się w trudnej ekonomicznie sytuacji, skupili swoje działania na komunikacji online z czytelnikami i czytelniczkami. Liczne działania podjęło wiele $\mathrm{z}$ ponad 13 tys. podmiotów wydawniczych działających pod koniec 2020 roku. Jak zastrzega portal Lubimyczytać.pl — rynek książki to nie tylko wydawcy, księgarnie i sprzedaż. To przede wszystkim czytelnicy, którzy coraz częściej szukają informacji o książkach na stronach internetowych. Serwis miesięcznie odwiedzało blisko 3,5 mln osób. Tylko w tym roku (2020) użytkownicy Lubimyczytać.pl przeczytali 3,5 mln książek (Sadowska 2020). W sieci dookoła książki działo się naprawdę dużo, a niektóre z tych działań zakończyły się sukcesem. Jako przykład można podać dane dotyczące Wirtualnych Targów Książki - BookTarg 2020, które odbyły się online w dniach 21-24 maja. Targi stanowiły zbiór połączonych ze sobą działań realizowanych przez trzech partnerów: Legimi (pierwszą księgarnię w Polsce oferującą dostęp do e-booków oraz audiobooków w abonamencie), portal Lubimyczytać.pl (ma obecnie milion zarejestrowanych kont) oraz Allegro. BookTarg oferował wirtualne spotkania z pisarkami i pisarzami, promocje na zakup książek i branżowe szkolenia. Wydarzenia zostały podzielone gatunkowo, aby konkretne grupy czytelnicze bez trudu trafiły na te eventy, które wiązały się $\mathrm{z}$ ich ulubionymi gatunkami literackimi. Dziewięć bloków tematycznych, ponad 60 spotkań autorskich, paneli dyskusyjnych i seminariów, 520 tys. sprzedanych książek, a przede wszystkim ponad 1,2 mln uczestników i uczestniczek - to najkrótsze podsumowanie drugiej edycji BookTargu, czyli Wirtualnych Targów Książki (Cieślik 2020). Dynamiczne działania w środowisku księgarskim zainicjował także jeden z największych dystrybutorów w Polsce - Azymut, który zaangażował się w dwie akcje: \#KsiążkaNaTelefon oraz festiwal Noc Księgarń. Pod względem reakcji podmiotów wydawniczych na pandemię szczególnie ciekawa wydaje się pierwsza z wymienionych. Akcja została wznowiona w październiku 2020 roku. Jesienią do kampanii prowadzonej przez Azymut przyłączyli się kolejni wydawcy, autorzy i media. Do tej pory informowały o niej między innymi TVN24, Polsat, Polskie Radio, „Gazeta Wyborcza”, „Polityka”, serwisy branżowe i media lokalne. Inicjatywę wspierali także pisarze i pisarki, wśród nich między innymi Mariusz Szczygieł, Zygmunt Miłoszewski, Michał Rusinek, Ałbena Grabowska, Justyna Sobolewska, Wojciech Chmielarz, Marcin Wroński czy Katarzyna Grochola (Dąbrowska 2021). W ramach akcji \#KsiążkaNaTelefon klienci mogą zamawiać tytuły wydane na papierze w księgarniach stacjonarnych, które 
uczestniczą w projekcie. Takie pozycje są specjalnie pakowane i wysyłane kurierem. W projekcie bierze obecnie udział ponad 260 księgarni i antykwariatów z całej Polski. W 2019 roku w ramach tej właśnie akcji organizowano także różne wydarzenia - spotkania, szkolenia, prezentacje i warsztaty (a było ich przeszło tysiąc) w samych księgarniach. Obecnie reaktywowana kampania wspomagana jest między innymi przez portal społecznościowy Facebook (zaplecze reklamowe) i ma na celu przeciwdziałanie skutkom pandemii COVID-19. Na Facebooku \#KsiążkęNaTelefon śledzi obecnie około 7,5 tys. osób, a w portalu Instagram ponad 1700 followersów. Reakcje i zainteresowanie tymi eventami i akcjami ze strony społeczności internetowej wykazują, jak bardzo współcześni czytelnicy i współczesne czytelniczki zmienili się pod względem otwartości na nowe technologie.

\section{Młodzi odbiorcy wideo w internecie}

Brak możliwości spędzania czasu jak dawniej, czyli na przykład wyjścia do kina czy na koncert, odwiedzenia księgarni bądź spędzenia czasu w bibliotece i w kawiarni, musiał wpłynąć na odbiorców wspomnianego przemysłu kulturalnego. Jak pokazuje Ogólnopolskie badanie, na potrzeby raportu „Polaków portfel własny - zakupy $w$ dobie pandemii”, przeprowadzone na zlecenie Santander Consumer Banku przez Instytut IBRiS pod koniec listopada 2020 roku, Polacy zaczęli bardziej powszechnie korzystać między innymi z platform wideostreamingowych. Odsetek osób nieposiadających żadnej subskrypcji tego rodzaju wyraźnie spada w przypadku osób zarabiających od 4000 do 4999 zł miesięcznie i Polaków osiągających dochody powyżej 5000 zł (wynosi odpowiednio: 33\% i 29\%). Można zaobserwować, że odbiorcy mediów, szczególnie tych wizualnych, przenoszą się do internetu. Jak podaje Google, mimo rekordowej oglądalności telewizji w marcu i kwietniu tego roku, co było spowodowane pozostawaniem w domach, najmniej czasu na telewizję poświęcają przedstawiciele pokolenia Z, czyli osoby w wieku 13-24 lat. Jednocześnie przeciętnie każdego dnia połowa tak zwanych light TV viewers w wieku od 18 do 55 lat ogląda treści wideo na YouTubie. Wiemy również, że dla 35\% light TV viewers w przypadku poszukiwania rozrywki pierwszym wyborem jest YouTube. Wydaje się także istotne, iż 55\% z nich, gdy chce się czymś zainspirować, wybiera właśnie platformę YouTube, a dla 53\% jest ona pierwszym wyborem, jeśli chodzi o naukę (Dąbrowska 2020). Dodajmy, że dane na temat tego, w jakim wieku są najbardziej zaangażowani czytelnicy i najbardziej zaangażowane czytelniczki w rynek książki, pokazują, że mamy w tym przypadku do czynienia (przynajmniej częściowo) z pokoleniami uczestniczącymi właśnie w opisywanych powyżej technologicznych przemianach na rynku mediów. Podsumowując rok 2020, Biblioteka Narodowa określiła bowiem, że w przedziale wiekowym 15-24 lat 22\% badanych zadeklarowało, że przeczytało w ciągu roku jedną książkę lub dwie, a 18\% wskazało, że przeczytało od trzech do sześciu książek w ciągu roku. W przedziale wiekowym 25-39 lat, 19\% zadeklarowało przeczytanie 
jednej książki lub dwóch, a 12\% — od trzech do sześciu tytułów. Jest to bez wątpienia grupa odbiorców przekazów medialnych, której pojawienie się na rynku badacz rynku książki Łukasz Gołębiewski słusznie przewidywał już kilkanaście lat temu:

To pokolenie świetnie przystosowane do nowej cyfrowej ery, bezbłędnie poruszające się w świecie bajtów i bitów, potrafiące wybierać, potrafiące szukać i selekcjonować, na bieżąco weryfikujące informacje [...]. Natychmiastowość to symbol nowego młodego człowieka. Teraz albo nigdy. Nie czekać. Dostać, nie wychodząc z domu, najlepiej nie wstając od komputera. (Gołębiewski 2008: 31)

\section{Książkowy zwiastun — próba definicji i cechy narzędzia}

Twór, jakim jest książkowy trailer, nazywany także teaserem (spot w wersji telewizyjnej), wideo-preview (zwiastun) czy też cinematic book trailers, wydaje się narzędziem do komunikacji o książce, które jest wręcz stworzone dla nowych, młodych grup odbiorców różnorakich mediów, w szczególności internetowych. Dla tych odbiorców jest to dodatek, paratekst jak najbardziej w rozumieniu twórcy tego terminu - Gérarda Genette'a - który opisywał go jako swoisty „akompaniament”(Genette 1991: 261) na przykład dla książki. Zwiastun staje się medialną eskortą dla tytułów książkowych na tym samym poziomie co, towarzyszące im już od lat, blurby, wywiady czy ilustracje, o których pisze w swojej książce Iwona Loewe (Loewe 2007: 32). W przypadku zwiastuna do książki już sam fakt, że przyjmuje on formę paratekstu kojarzonego dotąd z obrazem telewizyjnym lub kinowym — wizualnie dużo bardziej atrakcyjnym niż książka - sprawia, że zainteresowanie odbiorców rośnie. Zgodnie $\mathrm{z}$ hasłem Marshalla McLuhana: The medium is the message, moglibyśmy przyjąć, że samo określenie zwiastuna mianem teasera czy trailera wywołuje skojarzenie z nowoczesnym światem mediów internetowych i rozwiązań hipertekstowych, czyli utworów złożonych z fragmentów tekstu, które wskazują drogi do innych tekstów" (Dovey 2008: 158). Zadaniem teasera czy trailera jest bowiem nie tylko pobudzenie naszej ciekawości, poinformowanie o dacie premiery produktu, którego materiały te dotyczą, lecz także wskazanie dodatkowych informacji (z social mediów, oficjalnej strony internetowej tytułu czy z bloga szczegółowo opisującego produkcję), tak abyśmy wpadli w swego rodzaju sidła informacyjnego hype’u (zainteresowania wokół produktu). Jeżeli uznamy za prawdziwą teorię, która mówi o tym, że media kreują rzeczywistość poprzez przyciąganie uwagi odbiorców do konkretnych zagadnień, i przywołamy popularne stwierdzenie Bernarda Cohena, że „być może mass media nie decydują o tym, co ludzie myślą, ale mają zasadniczy wpływ na to, o czym myślą" (Dobek-Ostrowska 2001: 75), to stanie się jasne, że dzisiaj, w czasach wszechobecnych przekazów internetowych, takie narzędzie promocji jak filmowy zwiastun eskortujący książkę może zyskać na znaczeniu.

Nie jest to wynalazek nowy. W 2012 roku trailer do książki jako pomysł na promocję tytułu miał już dziesięć lat. Nazwa book trailer została opatentowana jako znak towarowy w 2002 roku przez Sheilę Clover z COS Productions (Sanders 2017: 70). 
Literacki zwiastun można zdefiniować jedynie przez analogię do zwiastuna filmowego - jest to krótka forma reklamowa, krótki materiał promocyjny, który ma zapowiedzieć premierę danej produkcji lub poinformować o niej, aby zaciekawić publiczność. Trailer nie powinien ujawniać zbyt wielu szczegółów fabularnych i zwykle odwołuje się do wywoływania emocji wśród widzów. Pierwszy literacki zwiastun powstał w 1994 roku. Był to trzyminutowy film promujący książkę Amnesia kanadyjskiego autora Douglasa Coopera (Pawlicka 2009). Kilkanaście lat temu, kiedy książkowy trailer jako forma komunikacji z czytelnikami w Polsce był jeszcze w zasadzie nieznany, specjalistka w zakresie promocji literatury Jacqueline Devai pisała w jednej ze swoich książek na temat book marketingu:

Pięć sekund nudnej informacji na ekranie może dłużyć się jak wieczność. Największym błędem, który autorzy popełniają podczas tworzenia zwiastunów do książek, jest niezrozumienie szybkiego montażu kinowych obrazów. Kto mógł przypuszczać dwadzieścia lat temu, że obecnie, aby skutecznie sprzedawać książki, musimy być ekspertami w każdej dziedzinie tworzenia mediów (Deval 2008: 243).

Dodajmy, że mówimy tu o okresie, kiedy tworzenie filmowych trailerów było działaniem często autorskim, bez wsparcia zewnętrznych firm, i okazywało się niewielką inwestycją. W tej samej książce badaczka przywołuje przypadek trailera stworzonego do książki A Season of Forgiveness przez Brendę Coulter, autorkę poczytnych romansów, które promują chrześcijańskie wartości.

Coulter spędziła na tworzeniu zwiastuna około 40-50 godzin, a koszty produkcji zamknęly się w kwocie 65 dolarów, które zainwestowała, aby zabezpieczyć prawa do licencjonowanej muzycznej ścieżki. Poza tym korzystała z udostępnionych za darmo zdjęć oraz dodatkowej muzyki, nie płaciła za specjalistyczne oprogramowanie, gdyż ograniczyła się do użycia darmowego programu Windows Movie Maker wbudowanego w system Windows. Kiedy materiał był już gotowy, autorka udostępniła go na platformach: YouTube, MySpace, AOL Uncut Movie, Google oraz na swoim blogu. Samo umieszczenie zwiastuna na platformie GodTube przyniosło jej 50 odtworzeń w ciągu 24 godzin (Deval 2008: 242).

\section{Ewolucja książkowego zwiastuna w stronę medium filmowego}

Opisana powyżej sytuacja wydarzyła się wiele lat temu. Od jakiegoś czasu zagraniczne trailery do książek coraz bardziej zbliżają się formułą, składowymi i wykonaniem do schematów wypracowanych przez lata w przemyśle filmowym. Tim Ferris, specjalista w zakresie produkcji zwiastunów, mówi wprost o tym procesie:

Profesjonalne filmowe trailery trwają nieco ponad dwie minuty, dlatego rekomendujemy, aby skracać książkowe preview do długości jednej minuty, często zmieniać ujęcia, zwracać uwagę na pokazanie okładki i kluczowych scen, stosować zewnętrzną narrację lektora, używać dodatkowych grafik, ciekawego tła oraz podkładu dźwiękowego pasującego do całości (Jelen i McCallister 2014: 221). 
W związku z krótkim czasem koncentracji na informacjach dostępnych online minutowe lub dwuminutowe wideo zwykle najmocniej działa na odbiorcę - dodaje Lorraine Phillips w książce Online Book Marketing (Phillips 2011: 155).

Dziś książkowe zwiastuny są produkowane przez specjalistyczne firmy w rodzaju Trailertothestars.com (firmą tą kieruje doświadczony hollywoodzki twórca i producent filmowy, Misty Tagart), a korzystanie $z$ tego rodzaju filmowego medium jest za granicą powszechne na przykład w największych księgarniach online (Amazon, Barnes\&Nobel), które udostępniają na swoich platformach specjalne miejsce do zamieszczania książkowych wideotrailerów. Specjaliści z Trailertothestars.com wiedzą, że dostępne dziś zwiastuny filmów kinowych mają zazwyczaj długość od półtorej do dwóch i pół minuty. Prócz nich istnieją także teasery (przyciągające uwagę odbiorców jeszcze na etapie pre-produkcji filmu), których czas trwania nie przekracza minuty. Krótsze materiały wideo nie ujawniają zbyt wiele, jeśli chodzi o fabułę zapowiadanego filmu, i bardzo często w ogóle nie bazują na materiałach, które ostatecznie znajdą się w kinowej wersji obrazu. Trzecim popularnym formatem wideo promującym filmy jest spot telewizyjny, którego rozpiętość czasowa waha się pomiędzy piętnastoma a 60 sekundami.

Książkowe trailery wykorzystują na różne sposoby większość przywołanych filmowych schematów, ale inspiracja kinowymi trailerami pod względem sposobu wykonania nie ogranicza się jedynie do wykorzystania tego samego formatu czasowego. Producenci z uznanej firmy producenckiej Film 14 wyróżniają animowane zwiastuny do książek (pozbawione aktorów, tradycyjnych efektów specjalnych itp.), previews bazujące na statycznych obrazach oraz takie zwiastuny, które z natury rzeczy mają być możliwie bliskie pod względem produkcyjnym ich kinowym odpowiednikom. Film 14 nazywa takie zwiastuny cinematic book trailers (Salway 2021).

Cinematic book trailers, podobnie jak trailery do filmów kinowych, pokazują jedynie zarys książkowej fabuły. Jeśli już sięga się w ich przypadku po konkretny wątek $\mathrm{z}$ powieści albo zbioru opowiadań, to jest to zwykle jedynie wprowadzenie któregoś z fabularnych konfliktów, ukazanie głównych bohaterów czy też przedstawienie tła, świata, w którym rozgrywa się akcja książki. Jako przykład właśnie takiego rozwiązania chciałem przywołać strukturę niezwykle popularnego trailera do książki (5,5 mln wyświetleń w serwisie YouTube od premiery w 2012 roku) Katie Alender As Dead As it Gets (cykl: Bad Girls Don't Die). Rolę protagonistki $\mathrm{w}$ tym półtoraminutowym materiale filmowym odgrywa, znana $\mathrm{z}$ młodzieżowych produkcji, aktorka, modelka i piosenkarka - Bella Thorne. Typowo filmowym rozwiązaniem jest bezpośredni zwrot do widzów, który rozpoczyna całe nagranie. Bella Thorne monologuje w zastępstwie lektora i opowiada o problemach nastolatków, tym samym natychmiast zwraca uwage grupy docelowej, do której kierowane jest to wideo. O tym, że mamy do czynienia z prawdziwie kinową produkcją, przekonują nas zdjęcia w plenerze, liczne rekwizyty, duża liczba drugoplanowych aktorów i aktorek, ale przede wszystkim - typowo filmowy szybki montaż. W ósmej sekundzie nagrania, tuż po zakończeniu długiego ujęcia ukazującego bohaterkę, zaczynają się 
teledyskowe, dynamicznie zmieniające się ujęcia. Następuje około 20 cięć, które nie pozwalają widowni oderwać się od prezentowanej filmowej narracji. Zmiana następuje dopiero w czterdziestej ósmej sekundzie, kiedy to przedstawiony zostaje zwrot akcji — oto dowiadujemy się, że monologująca bohaterka nie żyje.

Cinematic book trailers nawiązują w swej konstrukcji także do innych cech kinowych trailerów. Zwiastun As Dead As it Gets zbudowano na bazie trzech aktów. Składają się na nie przedstawienie bohaterów oraz książkowego settingu, zarysowanie głównego konfliktu i wprowadzenie w klimat opowieści (mroczny i gotycki). Podobne schematy produkcyjne obserwujemy również w przypadku jednej z najnowszych produkcji studia Film 14 - zwiastuna do młodzieżowej powieści The Land Without Color Benjamina Ellefsona. Zresztą sam autor książki wydaje się świadomy możliwości, jakie daje w komunikacji z publicznością prawdziwie filmowy trailer do książki. Zwiastun ma swoje miejsce na autorskiej stronie oraz na profilu Amazonu. Pomaga rozbudować społeczność fanowską i świetnie sprawdza się na platformach social mediów. Po premierze, kiedy fanfary ucichną, będzie nadal używany przy kampaniach reklamowych tworzonych w serwisach: Facebook, Twitter i YouTube, tak aby dotrzeć do nowych odbiorców (Salway 2021). Trailer do The Land Without Color został nakręcony przez duet filmowców Deka Brothers, znany z reklam, teledysków muzycznych, książkowych trailerów (między innymi dla wydawnictwa Penquin Books) i projektów filmowych (zdobywcy między innymi statuetki MTV Video Music Awards oraz nominacji w kategorii Brand Vision Vimeo Festival \& Awards).

W produkcji do książki Ellefsona zastosowano inne typowo filmowe rozwiązania techniczne. Użycie lektora komentującego z offu, czyli tak zwanego voice-overu, pomaga na przykład odnaleźć się w narracji trailera, poszerza jego ekspozycję, tłumaczy i dopowiada to, czego nie sposób pokazać w ciągu zaledwie półtorej minuty trwania obrazu. Znaczenie ma także odpowiednie wykorzystanie muzyki ilustracyjnej.

Cinematic book trailers poprzez swoją konstrukcję, rzeczywiście realizują te same funkcje w zakresie komunikacji z widownią co zwiastuny obrazów kinowych. Jak piszą specjaliści pracujący dla platformy filmowej StudioBinder, która daje między innymi możliwość korzystania z narzędzi do edycji wideo w chmurze:

Rolą filmowego zwiastuna jest wzbudzenie żywego, emocjonalnego zainteresowania danym projektem, dostarczenie widowni rozrywki (powinien być dziełem skończonym, zrozumiałym bez konieczności odnoszenia go do finalnego projektu, który promuje). (Kiraz 2020)

Tak jak w przypadku branży filmowej, gdzie występują wariacje zwiastunów o innym zakresie czasowym (chodzi tu o wspomniane teasery oraz spoty telewizyjne), tak i w przypadku previews książkowych spotykamy krótsze formy (czasami tworzone na potrzeby medium telewizyjnego, jak w przypadku powieści Under the Dome Stephena Kinga). Krótsze formy filmowe, jak teaser-trailer, mogą w przypadku książek być wykorzystywane w zastępstwie pełnowymiarowych trailerów typu cinematic book trailer (podczas gdy w kinematografii produkuje się różne typy zwiastunów, nie poprzestając na jednej formule). Za przykład tego rodzaju 
niech posłuży nam inny niezwykle popularny teaser-trailer książki, który osiągnął prawie 4,5 mln wyświetleń od czasu premiery na platformie YouTube (dostępny od 19 lipca 2011 roku). Mowa tu o materiale filmowym do książki Pete the Cat: Rocking in My School Shoes, który jednocześnie odgrywa rolę muzycznego klipu dla dzieci. Dwuwymiarowej animacji, której design dopasowano do konkretnej grupy młodszych odbiorców, towarzyszy minutowa piosenka zastępująca voice-over. Książkę duetu James Dean (ilustracje) oraz Eric Litwin (tekst) wydało wydawnictwo HarperCollins w serii HarperCollinsChildrens, a piosenka, która towarzyszy teaserowi, jest dostępna w całości do pobrania za darmo albo do odsłuchania między innymi na takich platformach jak Soundcloud czy Spotify. Zarówno piosenka, jak i opowieść zawarta w animacji uczą, bawiąc. Śledzimy losy kota, który wybiera się do szkoły, a poza salą zajęć poznaje inne ciekawe i ważne dla uczniów miejsca - bibliotekę, plac zabaw czy stołówkę. Na ten muzyczno-filmowy zabieg (wykorzystanie $\mathrm{w}$ trailerze piosenki) trafimy także w wielu trailerach kinowych. Za przykład może nam posłużyć zwiastun filmowej adaptacji bestsellera Stiega Larssona, The Girl with a Dragon Tattoo. W materiale tym zrezygnowano $\mathrm{z}$ dopowiadającej narracji lektora na rzecz ścieżki dźwiękowej - specjalnie przygotowanej wersji piosenki grupy Led Zeppelin The Immigrant Song zaśpiewanej przez niezależną artystkę Karen O, a zmiksowanej i wyprodukowanej przez duet Trent Reznor i Atticus Ross.

\section{Zakończenie}

Abraham Moles pisał już w 1967 roku o tym, że współczesna kultura stała się całością nieuporządkowaną, o strukturze mozaikowej, gdzie przemieszane są elementy różnej wartości (Moles 2003: 1991; za: Filipiak 2003). Internet już wiele lat temu stał się takim nieuporządkowanym odbiciem różnych aspektów przemysłu kulturalnego. W czasie pandemii zaczął niespodziewanie spełniać funkcję podstawowej przestrzeni, w której ramach można było obcować ze współczesną kulturą. Postępujący w ciągu ostatniego roku rozwój technologiczny wydaje się przyspieszać przemianę sieci z mozaikowego medium, w którym każdy amator i każda amatorka czuje się twórcą czy artystką, w medium, które wypełniają coraz bardziej dopracowane i specjalistycznie wyprodukowane parateksty. Podobnie działo się z innymi przestrzeniami mediów i kultury, na przykład kinem czy telewizją. Po okresie nieuporządkowanych prób i błędów z czasem powstały sformalizowane i wyspecjalizowane struktury, które w sytuacji oddziaływania na odbiorcę stawały się skuteczniejsze niż kiedykolwiek wcześniej. Profesjonalne, coraz bardziej filmowe zwiastuny do książek mogą także wkrótce wyewoluować z postaci paratekstów czy dodatków do formy autonomicznych tekstów kultury. Takich, które analizuje się zarówno w kontekście danej książki (przyczyny ich powstania), jak i bez tego kontekstu - jako produkcje istotne same w sobie, jak trailery do filmów kinowych czy wideoklipy stworzone do piosenek.

Prawdziwie filmowe trailery do książek mogą w najbliższych latach stać się istotnym medium i elementem kultury czytania również w Polsce. Jeżeli zwrócimy uwa- 
gę na badania Cisco Survey, jeszcze z 2013 roku, które przytaczają w książce Build Your Author Platform Carole Jelen oraz Michael McCallister, to zauważymy, że już wiele lat temu przewidziano, iż do 2017 roku ponad 69\% ruchu w internecie będzie generowało wideo. W tym samym badaniu wskazano, że klienci coraz częściej wolą poszukiwać towarów online i zdobywać o nich informacje, zamiast dokonywać tego rodzaju operacji w sklepach (Jelen, McCallister 2014: 215). Nowe pokolenia bardzo szybko dostosowują się do nieznanych wcześniej sposobów dystrybucji książek online. Chciałem w tym miejscu przywołać dane, które podsumowują rok 2020 w przypadku działalności platformy ArtRage, w której ramach regularnie odbywają się akcje o nazwie BookRage oraz QuickRage. Przedsięwzięcie to polega na stworzeniu specjalnej oferty zakupu e-booków połączonych w pakiety tematyczne za cenę, którą ustala sam klient (dzieląc zainwestowaną sumę pomiędzy na przykład wydawców, autorów, wskazane organizacje charytatywne oraz twórców BookRage). Jak pisze Robert Drózd na stronach Świata Czytników: „sprzedaż książek za pośrednictwem ArtRage w 2020 wyniosła 14217 pakietów na łączną kwotę 1968050 złotych. Pojedynczych książek wychodzi 50-60 tys." (Drózd 2020).

Jeśli wziąć pod uwagę wartość rynku e-booków w Polsce, szacowaną na około 100 mln złotych rocznie, to wygląda na to, że również tak niszowa inicjatywa jak ArtRage wypracowała sobie około dwuprocentową niszę, a klienci zaczęli traktować tę inicjatywę jako kolejny, sprawdzony i technologicznie dopracowany kanał zakupowy.

Jelen i McCallister piszą w swej książce o tym, że odwiedzający stronę internetową, którzy mają szansę obejrzeć wideo prezentujące dany produkt, wykazują o 85\% większą chęć do jego zakupu niż ci, którzy takiego wideo nie widzieli. Dodatkowo 96\% tych, którzy dokonują zakupów online, to ludzie regularnie oglądający wideo w internecie (Jelen, McCallister 2014: 216). Skoro tak, to z pewnością warto przyjrzeć się bliżej ewolucji i kierunkom rozwoju narzędzia do komunikacji z czytelnikami, jakim jest filmowy zwiastun książki, a w szczególności cinematic book trailer. Narzędzie to na chwilę obecną ciągle stanowi zaledwie medialną eskortę książki, jednak wkrótce może się stać samowystarczalnym, technicznie dopracowanym i inspirującym tekstem kultury.

\section{Bibliografia}

Cieślik E. (2020): BookTarg - podsumowanie wirtualnych targów książki Allegro, lubimyczytać.pl i Legimi, https://lubimyczytac.pl/booktarg-podsumowanie-wirtualnych-targow-ksiazki-allegro-lubimyczytac-pl-i-legimi (dostęp: 10.04.2021).

Dąbrowska J. (2020): Polacy spędzaja ponad 40 min dziennie na oglądaniu serwisu YouTube, https://www. wirtualnemedia.pl/artykul/youtube-w-polsce-ile-czasu-spedzamy-oferta (dostęp: 10.05.2021).

Dąbrowska J. (2021): Połowa Polaków płaci za usługi cyfrowe. Co trzeci subskrybuje serwisy z serialami i filmami, https://www.wirtualnemedia.pl/artykul/polowa-polakow-placi-za-uslugi-cyfrowe-co-trzeci-subskrybuje-serwisy-z-serialami-i-filmami (dostęp: 10.05.2021).

Deval J. (2008): Publicize Your Book (Updated): An Insider's Guide to Getting Your Book the Attention It Deserves, New York.

Dobek-Ostrowska M. (2001): Nauka o komunikowaniu. Podstawowe orientacje teoretyczne, Wrocław. 
Dovey J. (2008): Uwagi na temat hipertekstualnej teorii narracji, [w:] Ekrany piśmienności. O przyjemnościach tekstu w epoce nowych mediów, red. A. Gwóźdź, Warszawa.

Drózd R. (2020): BookRage podsumowuje rok 2020, https://swiatczytnikow.pl/bookrage-podsumowuje-rok-2020-sprzedaz-e-bookow-za-prawie-2-miliony-zl/(dostęp: 10.05.2021).

Filipiak M. (2019): Homo communicans. Wprowadzenie do teorii masowego komunikowania, Lublin.

Genette G. (1991): Introduction to the Paratext, „New Literary History” 22, nr 2.

Gołębiewski Ł. (2008): Śmierć książki. No future book, Warszawa.

Jelen C., McCallister M. (2014): Build Your Author Platform, Dallas.

Kiraz S. (2020): How to Make a Movie Trailer that Grabs Attention, https://www.studiobinder.com/ blog/how-to-make-a-movie-trailer/ (dostęp: 10.05.2021).

Loewe I. (2007): Gatunki paratekstowe w komunikacji medialnej, Katowice.

Moles A. (1967): Sociodynamique de la culture, Berlin.

Pawlicka U. (2009): Trailery literackie - o reklamie literatury pisanej „żywa kamerą”, http://niedoczytania.pl/trailery-literackie-o-reklamie-literatury-pisanej-zywa-kamera (dostęp: 10.05.2021).

Phillips L. (2011): Online Book Marketing, Atlanta.

Sadowska I. (2020): Raport z branży. Różne oblicza rynku książki w czasie pandemii, https://lubimyczytac.pl/raport-z-branzy-rozne-oblicza-rynku-ksiazki-w-czasie-pandemii (dostęp: 10.05.2021).

Salway P. (2021): Why Book Trailers And Cinematic Author Videos Are The New Book Launch, https:// film-14.com/2021-film-adaptations/ (dostęp: 10.05.2021).

Salway P. (2021): Benjamin Ellefson Author, https://film-14.com/the-land-without-color/ (dostęp: 10.05. 2021).

Sanders L. (2017): How to develop an effective author brand, [w:] Writer's Market 2017, red. R. Brewer, Ohio.

Toffler A. (1986): Trzecia fala, przeł. E. Woydyłło, Warszawa.

\section{Cinematic features of the book trailer}

\section{Summary}

In a broader sense, the text deals with the growing popularity of video trailers for books, explains their functions and defines their place in the sphere of reading culture. In a more narrow sense - the cinematic features of literary trailers were analyzed and compared with traditional film trailers. The article presents a preliminary analysis of various technical aspects of this type of production, with particular emphasis on tools such as the cinematic book trailer. The discussed themes are related to issues which are fundamental for creating effective communication in the dynamically developing online space: communication between readers, authors and producers of book trailers, which in the near future may become one of the most popular and refined forms of promoting literature on the internet.

Keywords: book, teaser, paratext, communication, trailer, reading culture, advertising, promotion, reading, book on the internet, film trailer. 